\title{
The role of mangrove in the French Guiana shrimp fishery
}

\author{
Diop Bassirou ${ }^{1,{ }^{*}}$, Sanz Nicolas ${ }^{2}$, Blanchard Fabian ${ }^{3}$, Walcker Romain ${ }^{4}$, Gardel Antoine ${ }^{5}$ \\ ${ }^{1}$ Domaine de Suzini, CNRS, UMRS 3456, LEEISA, Cayenne, French Guiana \\ ${ }^{2}$ Université de Guyane, UMRS 3456, LEEISA, Cayenne, French Guiana \\ ${ }^{3}$ Domaine de Suzini, Ifremer, UMRS 3456, LEEISA, Cayenne, French Guiana \\ ${ }^{4}$ Université EcoLab, UniversitÃ de Toulouse, Toulouse, France \\ ${ }^{5}$ Centre de Recherche de Montabo, CNRS, UMRS 3456, LEEISA, Cayenne, French Guiana \\ * Corresponding author : Bassirou Diop, email address : diop.bassirou@gmail.com
}

\begin{abstract}
This paper investigates the role of mangrove as an habitat in the evolution of the French Guiana shrimp stock to explain the recent collapse of shrimp production. To achieve our aim, we use the open access fishery model developed by Barbier and Strand [1998. "Valuing Mangrove-Fishery Linkages-A Case Study of Campeche, Mexico." Environmental and Resource Economics 12: 151-166] and integrate mangrove surface into the shrimp natural growth function. This enables to account directly for the effects of mangrove surface changes on the stock dynamics and thus production. Our results indicate that financial losses in the French Guiana shrimp fishery increase when mangrove surface decreases and are mitigated when mangrove surface increases. We show that changes in mangrove surface are not determinant in explaining the collapse of the shrimp stock but that mangrove should be preserved as it still mitigates the decline of the stock.
\end{abstract}

Keywords : Shrimp fishery, mangrove, habitat, production function, open access

JEL Classification : Q22 


\section{Introduction}

Shrimp is nowadays the most consumed marine resource in the world. It represents the third export sector of the French Guiana and remains one of its main industrial sectors. However, the French Guyana shrimp fishery has encountered heavy difficulties in the past two decades. The globalization of the shrimp market, which has led to a decrease of $50 \%$ in real prices since 1997, and the long-term increase in fuel prices worldwide, though the 2007 crisis and its consecutive growth slow down has weakened this phenomenon, partly explain the economic problems the fishery has known. However, shrimp prices are now recovering on the US market. Facing this situation, some management rules were progressively adopted or reinforced starting from the creation of the Exclusive Economic Zone in 1977. A total allowable catch (TAC) system was implemented for both the brown and the pink shrimps in 1983 and the management of the fishery is now in compliance with the European legislation. Moreover, some spatial restrictions, forbidding trawling activities in specific coastal zones, were also imposed. The above measures have indeed led to the reduction of fishing effort and harvest levels. The number of active vessels has notably been diminished.

Indeed production has decreased from 3926 tons in 1990 to 1323 tons in 2009 (see Table A1.) and to less than 800 tons in 2015. Effort and biomass have followed the same trend in spite of restrictions and management rules.

The proximity between the French Guiana coast and the Amazon estuary results into the presence of a muddy corridor bounded by a red line (see Figure 1). The Fluid mud is transported along the coasts of the Guianas by a complex interaction of waves, and wind-generated coastal currents (Anthony et al., 2010). This results in a coast partly covered by mangroves.

In French Guiana the mangroves stretch for $600 \mathrm{~km}^{2}$ and colonize almost $75 \%$ of the coastline (Day et al., 1987). Mangroves provide ecosystem services such as carbon sink, nursery, shoreline stabilization and protection and play a vital role in the ecological balance. In French Guiana, mangroves are still not threatened by human activities. However, knowing that $90 \%$ of the population live on the coastal area, the demographic growth (3 to $4 \%$ per year) jeopardizes this situation considering the potential future coastal anthropization. Moreover, large natural variations of the mangrove areas have been recently quantified in French Guiana and related to oceanographic phenomenons (Walcker et al., 2015). These large variations of the mangrove surface should allow us to detect the relationships between fishery productivity levels and mangrove surfaces. Moreover, mangroves entail sediments that come from the huge mud discharge of the Amazon River located close to the fishing zone. Indeed they are considered important nursery habitats for 


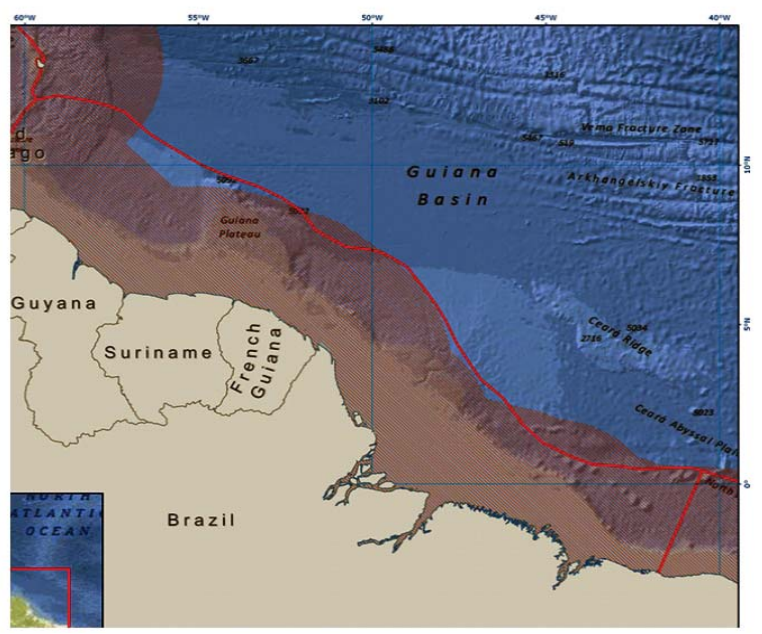

Figure 1: The Gianas-Brazil shrimping grounds

many marine species (Mumby et al., 2004; Faunce and Serafy, 2006; Serafi et al., 2015) and particularly for the shrimp.

Ecological dynamics of the fishery were investigated (Béné, 1997; Sanz et al., 2016). Several environmental factors, acting as forcing factors were correlated to the fishery production. Actually increasing trends in sea surface temperatures were observed, explaining at least partially the decrease in the shrimp fishery production. It was shown that local rivers and the Amazone play also a role. However authors have shown the importance that mangrove plays as nursery habitat in the shrimp fishery production in various areas in Indian Ocean (Turner, 1977; Pauly and Ingles, 1986; Camacho and Bagarinao, 1987; Rönnbäck, 1999). This question was never been attacked in the Guiana continental shelf.

The main purpose of this paper is to suggest an approach for evaluating the impact of mangroves on the shrimp production. A bioeconomic model is developed in which we firstly extend a standard fishery model by including the mangrove surface into the renewal resource of the shrimp, as Barbier and Strand (1998). We then analyze how losses and gain in mangrove area impact this fishery.

The French Guiana shrimp fishery is presented in Section 2. A extended bioeconomic model of fisheries in which we define linkages between the fishery and the mangrove is developed in section 3. Section 4 presents the main empirical results of the French Guina fishery managed under open access completed with a comparative static effect of fluctuations in the mangroves area. The paper is summarised in a last section with a discussion and policy 
implications of our results.

\section{The French Guiana shrimp fishery}

Two shrimp species are mainly exploited in the French Guiana fishery, the brown and the pink shrimps (resp. Farfantepenaeus subtilis and Farfantepenaeus brasiliensis). The French Guiana shrimp fishery started in the late 1960's with the US fleet activity. All the vessels are floridian shrimp trawlers, each using two trawls at the same time. Japanese vessels also exploited shrimps, but the whole fleet became progressively French between 1970 and 1990. Over this period, the US-Japanese fleet increased up to 80 trawlers. Since 1992, the whole fleet is only composed with French trawlers targeting shrimps on the continental shelf. The stock assessment has been firstly performed each two years by a working group within the FAO institutional and international framework of the Western Central Atlantic Fishery Commission (WECAFC) up to 1999, and has then been undertaken by the Ifremer (French institute of research for the exploitation of the sea) for management advice since the 1980's, allowing for a strong knowledge of the population. The method used for assessment is the well-known "Virtual Population Analysis" (VPA), carried out on a monthly step basis which allows to obtain the recruit abundance as well as the spawning stock biomass and the fishing mortality.

Table A1 (see Appendix) shows series of the shrimp biomass, catches, effort and mangroves areas for the period 1990-2009 obtained respectively from Ifremer and National Center for Scientific Research : CNRS (Walcker et al., 2015). Trends in series are shown in Figure 1. The biomass has steadily decreased over years though the effort and catch levels have followed quite the same trend. Yet, a total allowable catch (TAC) of 4108 tons for brown and pink shrimps has been adopted, of which 108 tons can be caught by neighboring countries (Surinam, Trinidad, Barbade). Compared to the historical catch, the TAC level has never been fully achieved. This TAC level has not been changed until 2011, facing the decline of the recruitment, and consequently of the spawning biomass, the TAC was reduced at 3317 tons in 2013 and at 3100 tons in 2014.

In 1991, a license system was introduced for both species. The main objective was initially to limit the number of vessels in order to protect the shrimp resource. Licenses are attributed without any fee. However, the license system did not seem to be in fact an active or efficient resource management tool. Indeed, the year abundance of shrimp is mainly correlated with recruitment but not with effort like e.g. the number of vessels or the 


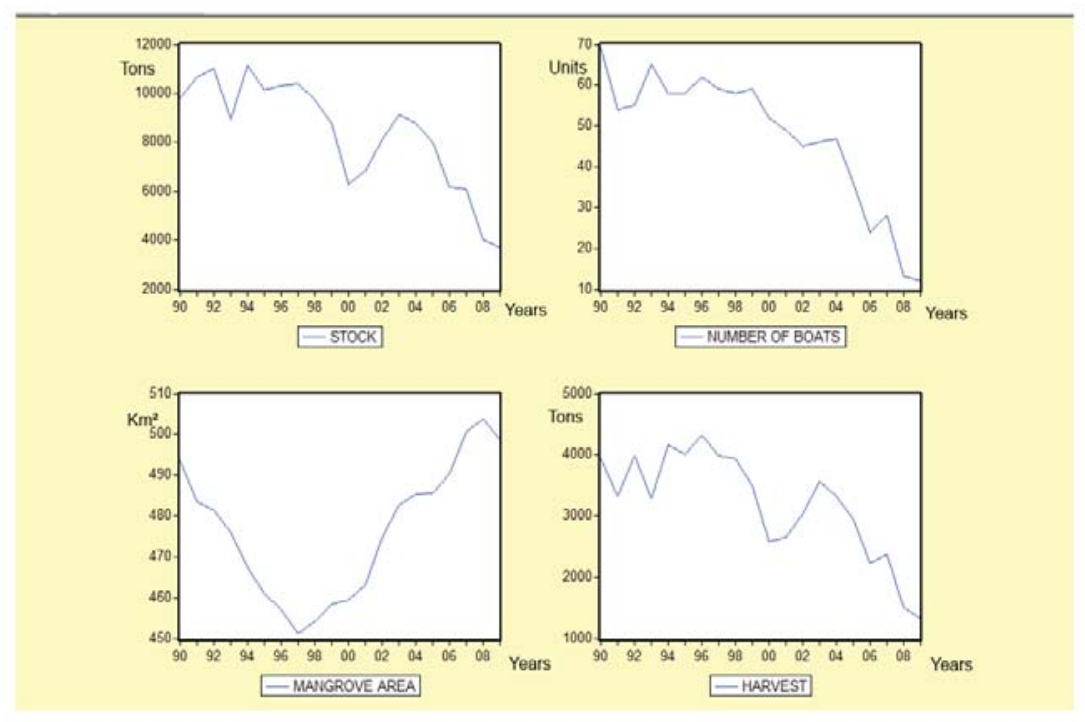

Figure 2: Historitical path in French Guiana over 1990-2009 : Effort, Stock, Harvest levels, and Mangrove areas

number of days at sea. The number of licenses was slightly reduced from 69 in 1991 to 63 in 1999, and to 49 in 2008, 40 in 2011 and 31 in 2014. During this period, the number of active shrimp trawlers was less than the number of licenses (less than half in 2006). The license system could have been a tool to adjust the number of vessels in order to improve economic results, but this objective was not explicitly addressed by the management system as the common fishery policy target is to reach the maximum sustainable yield (maximize the catches) and not the maximum economic yield (maximize the profit). Finally, there exist also some spatial restrictions: in order to limit the impact of trawling on juvenile shrimps and avoid conflicts with the coastal small-scale fishery, trawling is forbidden in coastal waters less than 30 meters deep. This rule is more restrictive than the spatial limitation applied to trawlers in European waters. All in all, the economic dynamics of the fishery has been characterized by a diminution of the fleet size, to concentrate the fishing activities on a reduced number of profitable vessels (around thirty). 


\section{The model}

We consider changes in the biomass of a shrimp stock over time come from extended renewal resource dynamics, and harvesting. This can be explained by the following equation:

$$
X_{t+1}-X_{t}=F\left(X_{t}, M_{t}\right)-H\left(X_{t}, E_{t}\right)
$$

where $X_{t}$ and $X_{t+1}$ are respectively the total biomass at the period $\mathrm{t}$ and $\mathrm{t}+1$, $M_{t}$ is the mangrove area in period t, and $H_{t}$ is the total catch in period t, a function of the stock $X_{t}$ in period $\mathrm{t}$, and of the fishing effort in period $\mathrm{t}, E_{t}$. We assume here the number of participating vessels as effort units according to Bjørndal and Conrad (1987) who consider that is an appropriate measure of effort.

Assuming the mangroves as growth areas that feed shrimps and that play vital role in ecological balance, we extend the standard Gordon and Schaefer model (Gordon, 1954; Schaefer, 1954, 1957) to consider the impact of mangrove on the renewal resource dynamics function through the carrying capacity (see Barbier, 1994, Barbier and Strand, 1998). The renewal resource dynamics of the biomass will be explained by discrete-time of the extended logistic growth function as follows:

$$
F\left(X_{t}, M_{t}\right)=r X_{t}\left[K\left(M_{t}\right)-X_{t}\right]
$$

where $r$ is the intrinsic growth rate and $K$ is the environment carrying capacity. The harvest in period $t$ will be given by the following standard Schaefer production function:

$$
H_{t}=q E_{t} X_{t}
$$

where $q$ represents the catchability coefficient.

Assuming a proportional and positive relationship between mangrove and carrying capacity $\left(K\left(M_{t}\right)=\alpha M\right)$ with $\alpha>0$, and inserting Eq. (3) into Eq. (1), the stock dynamics equation becomes:

$$
X_{t+1}-X_{t}=r X_{t}\left(\alpha M_{t}-X_{t}\right)-q E_{t} X_{t}
$$

These equations describe the relationship between mangrove and the shrimp fishery. And we assume a steady-state condition which will be one of the long run equilibrium of our model. Furthermore the management of the French Guiana shrimp fishery is regulated through a quota of catches and a license system. We will consider in the next sections an open access equilibrium. These considerations will lead to analyze this fishery through the 
mangrove dynamics and to assess the economic consequences of variations in mangroves.

Smith (1969) views changes in fishing effort as determined by the level of profits. In the same way we suppose that fishing effort next period will fit in reaction the profit generated in current period (Clark, 1976; Conrad, 1995; Barbier and Starnd, 1998). With $p$ the output price and $c$ the cost per unit effort, the effort adjustment can be written as follows:

$$
E_{t+1}-E_{t}=n\left[p h\left(X_{t}, E_{t}\right)-c E_{t}\right]
$$

where $n$ is a positive adjustment parameter scaled in effort.

\subsection{Open access}

In the following section the open access French Guiana shrimp fishery is studied using the Gordon-Schaefer model specification. The model allows for discussing the steady state equilibrium and is specified in discrete time. The equilibrum under open access fishery is known as the bioeconomic or bionomic equilibrium (Gordon, 1954) and can be obtained when profits are equal to zero, or harvest equal to renewal resource. Vessels will enter the fishery and entry will proceed until effort is earning its opportunity cost. In the long-run open access of the French Guiana shrimp fishery, we consider $X_{t+1}=X_{t}=X, E_{t+1}=E_{t}=E$ and $M_{t+1}=M_{t}=M$. Assuming a constant output price per unit harvested $p$ and a constant cost per unit effort $c$ the profit can be written as:

$$
\pi_{t}=p H_{t}-c E_{t}
$$

where $p$ is the unit price of harvest and $c$ the unit cost per vessel. Replacing $H_{t}$ in (6) by (3), applying the free entry equilibrium condition under open access $\left(\pi_{t}=0\right)$, and isolating $X$, enables to find the expressions for the open access stock level:

$$
X_{O A}=\frac{c}{p q}
$$

The expression of the stock depends only on economic and technological parameters. The stock level under open access will be even weaker than the shrimp has a high price, easily catchable and low cost. Applying the steady state equilibrium conditions $\left(X_{t+1}=X_{t}=X\right)$ to Eq. (1) and isolating $E$ leads to the open access fishing effort level:

$$
E_{O A}=\frac{r}{q}(\alpha M-X)
$$




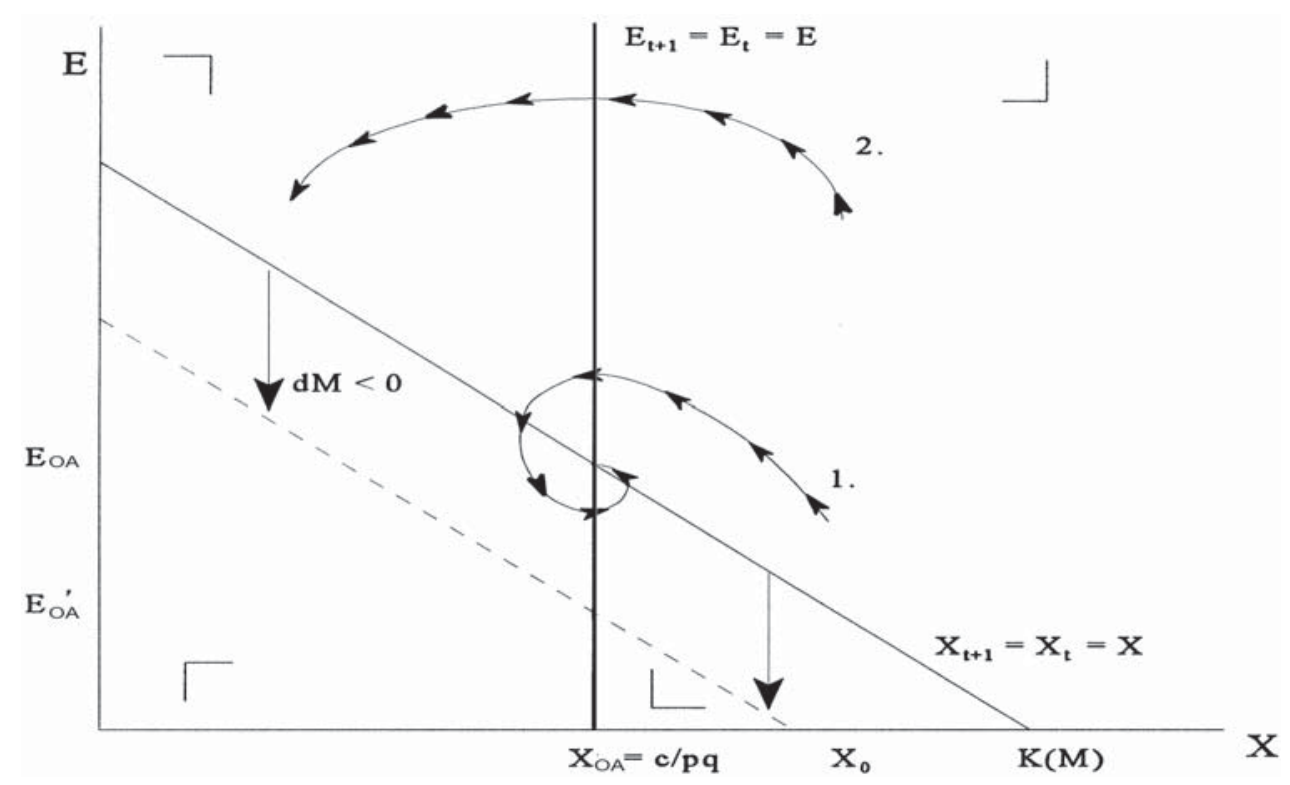

Figure 3: Effect of a change in mangrove area

Lastly, the expression of $H_{O A}$ can be obtained by substituting Eq. (7) and (8) into Eq. (3) gives the expression of the open access harvest level:

$$
H_{O A}=\frac{r c}{p q}(\alpha M-X)
$$

\subsection{Comparative static effect of fluctuation in man- grove area}

Indeed from Equation (8) we obtain the comparative static effect of a change in the mangrove area on the equilibrium level of fishing effort, $E_{O A}$ as follows:

$$
\begin{aligned}
& E_{O A}=\frac{r}{q}\left(\alpha M-X_{O A}\right) \\
& q \mathrm{~d} E_{O A}-r\left(\alpha \mathrm{d} M-\mathrm{d} X_{O A}\right)=0
\end{aligned}
$$

or

$$
\frac{\mathrm{d} E_{O A}}{\mathrm{~d} M}=\frac{\alpha r}{q}>0
$$

Equation (10) confirms that loss or gain of the mangrove area results respectively in lower or higher level equilibrium fishing effort. We can know derive the comparative static effect in the harvest and gross revenue of the fishery. 
From Equation (3) we can write:

$$
\mathrm{d} H_{O A}=q X_{O A} \mathrm{~d} E_{O A}=\alpha r X_{O A} \mathrm{~d} M=\frac{\alpha r c}{p q} \mathrm{~d} M
$$

We can easily derive change in gross revenue as follows:

$$
p \mathrm{~d} H_{O A}=\frac{\alpha r c}{q} \mathrm{~d} M
$$

We know $\beta_{1}=\alpha q$ and $\beta_{2}=-q^{2} / r$ and setting $\beta_{1} / \beta_{2}=-\alpha r / q$ we can rewrite Equations (11) and (12) as follows:

$$
\begin{array}{r}
\mathrm{d} H_{O A}=-\frac{c \beta_{1}}{p \beta_{2}} \mathrm{~d} M \\
p \mathrm{~d} H_{O A}=-\frac{c \beta_{1}}{\beta_{2}} \mathrm{~d} M
\end{array}
$$

Equation (8) gives a relationship between effort, stock and mangrove area where the stock level is supposed constant in the long run equilibrium. Figure 3 draws the equilibrium conditions in $(X, E)$ space. Since $E_{t+1}=E_{t}=E$ the curve is a vertical line that intersects the abscissa axis at point $X_{O A}=\frac{c}{p q}$. And the $X_{t+1}=X_{t}=X$ is a downward curve because of the negative relation between $E$ and $X$ in Equation (8). Two trajectories are represented, given an initial level of stock $X_{0}$. The first trajectory (1) converges towards open access $\left(X_{O A}, E_{O A}\right)$ equilibrium in spiral manner. The second trajectory (2) is rather unstable. It can corresponds to a high level of effort and can lead to a decline of the fishery. And a loss or a gain in mangrove area will impact directly the carrying capacity, and will shift up or down the $X_{t+1}=X_{t}=X$ curve. The equilibrium $X_{O A}$ will not change but this leads to a lower level of effort $E_{O A}^{\prime}$ and lower initial stock in long run equilibrium.

\section{Empirical results}

The steady state condition (assuming shrimp stock is constant $X_{t+1}=X_{t}=$ $X$ in the long run equilibrium) in the model allows for the relation between production, effort and mangrove. The relationship is as follows:

$$
H_{t}=q \alpha E_{t} M_{t}-\frac{q^{2}}{r} E_{t}^{2}=\beta_{1} E_{t} M_{t}+\beta_{2} E^{2}
$$


We first use ordinary least squares (OLS) to estimate the harvest production function (13) over the period 1990-2009. We use time series on shrimp harvest, effort and mangrove area. As we suppose that the French Guiana shrimp fishery operates during the studied period under open access, harvest and effort levels during that period satisfy both the open access equilibrium $\left(\pi_{t}=0\right)$. We can thus derive the corresponding level of cost each year that satisfies $\pi_{t}=0$. From Equation (6) we isolte $c$ and obtain the following expression $c=p H / E$ using historitical data of the fishery. The cost levels are shown on Table A2 (see Appendix). The parameters $\beta_{1}$ and $\beta_{2}$ indicate values that are statistically significant at $5 \%$ level. Significance level of coefficients denotes a good specification of the model and well suported data. Assumption of positive impact of mangrove on carrying capacity is strenghthened by the positive sign of $\beta_{1}$. The marginal productivity are calculated based on the mean number of vessels (45.35 vessels), the mean annual harvest (3099 tons), and the mean mangrove area $\left(474 \mathrm{~km}^{2}\right)$. And output elasticity estimates are shown in Table 1.

Table 1 : Estimates of the relationship between shrimp harvest, effort and mangrove area

\begin{tabular}{|c|c|}
\hline & $H=\beta_{1} E M+\beta_{2} E^{2}$ \\
\hline$\beta_{1}=q \alpha$ & $0.21(0.000)$ \\
\hline$\beta_{2}=-\frac{q^{2}}{r}$ & $-0.66(0.002)$ \\
\hline Number of observations 20 & F statistic $\quad 27.21$ \\
\hline$R^{2} \quad 0.78$ & $R^{2}$ adjusted $\quad 0.76$ \\
\hline JB $\quad 0.79$ & Q-Stat 4.73 \\
\hline $\mathrm{LM}(\mathrm{ARCH}) \quad 1.55$ & DW $\quad 1.36$ \\
\hline $\begin{array}{l}\text { Marginal productivity estimates (at means } \\
\mathrm{MP} M=\frac{\delta H}{\delta M}=\beta_{1} \mathrm{E}=9.75 \text { tons } / \mathrm{Km}^{2}\end{array}$ & $\mathrm{MP}_{E}=\frac{\delta H}{\delta E}=\beta_{1} \mathrm{M}+2 \beta_{2} \mathrm{E}=42.19$ tons $/$ boat \\
\hline $\begin{array}{l}\text { Output elasticity estimates } \\
\epsilon_{H M}=\frac{\delta H}{\delta M} * \frac{M}{H}=1.49\end{array}$ & $\epsilon_{H E}=\frac{\delta H}{\delta E} * \frac{E}{H}=0.61$ \\
\hline
\end{tabular}

The results of our estimation show two coefficients and three bioeconomic parameters $(\alpha, q$, and $r)$. We will not need to evaluate these parameters because a static comparative effects of change in mangrove area allows for simulating straightforward the marginal change in the mangrove area. The output elasticity for the mangrove area (1.49) indicate that a decline in the French Guiana mangroves has a more than proportionate impact on harvest 
in French Guiana shrimp fishery. However the impact of mangrove fluctuation during the 1990-2009 period was relatively small. Only $2 \%$ of the total surface of the mangrove was observed between 1990 and 2009. This situation suggests that the corresponding gain or loss in fishery harvest was about $3 \%$. The positive output elasticity for effort (0.61) indicates the decrease in fishing effort over the period had a relative negative impact on shrimp harvest. As the number of vessels decreased by $80 \%$, the corresponding loss in shrimp harvest was $48.8 \%$.

Table 2: Simulation results for the effects of mangrove on the OA equilibrium

\begin{tabular}{|c|c|c|c|c|c|}
\hline \multirow{2}{*}{\multicolumn{6}{|c|}{$\begin{array}{l}\text { Paremeter estimates } \quad \beta_{1}=0.21 \\
\qquad \beta_{2}=-0.66 \\
\text { Simulation estimates of marginal change in the mangrove area }(\mathrm{d} M)\end{array}$}} \\
\hline & & & & & \\
\hline year & price $(p) € / k g$ & Cost $(\mathrm{c}) € /$ vessel & $\mathrm{d} H_{O A}$ & $p \mathrm{~d} H_{O A}$ & Change (\%) \\
\hline 1990 & 8.34 & 474,533 & 12,795 & 106,710 & 0.32 \\
\hline 1991 & 8.33 & 399,960 & 10,784 & 89,830 & 0.32 \\
\hline 1992 & 8.09 & 467,461 & 12,604 & 101,966 & 0.31 \\
\hline 1993 & 8.62 & 409,137 & 11,032 & 95,095 & 0.34 \\
\hline 1994 & 10.35 & 623,400 & 16,809 & 173,973 & 0.40 \\
\hline 1995 & 10.31 & 599,175 & 16,156 & 166,568 & 0.40 \\
\hline 1996 & 10.06 & 630,280 & 16,995 & 170,969 & 0.39 \\
\hline 1997 & 10.53 & 607,993 & 16,394 & 172,628 & 0.41 \\
\hline 1998 & 10.43 & 595,568 & 16,059 & 167,495 & 0.40 \\
\hline 1999 & 9.93 & 502,976 & 13,562 & 134,670 & 0.38 \\
\hline 2000 & 11.08 & 439,849 & 11,860 & 131,408 & 0.46 \\
\hline 2001 & 9.63 & 369,987 & 9,976 & 96,068 & 0.37 \\
\hline 2002 & 7.98 & 351,929 & 9,489 & 75,722 & 0.31 \\
\hline 2003 & 7.45 & 384,052 & 10,355 & 77,144 & 0.29 \\
\hline 2004 & 7.19 & 346,674 & 9,347 & 66,363 & 0.28 \\
\hline 2005 & 7.1 & 302,830 & 8,165 & 57,971 & 0.27 \\
\hline 2006 & 6.99 & 225,098 & 6,069 & 42,422 & 0.27 \\
\hline 2007 & 6.96 & 238,960 & 6,443 & 44,843 & 0.27 \\
\hline 2008 & 7.28 & 157,838 & 4,256 & 30,983 & 0.28 \\
\hline 2009 & 6.63 & 127.123 & 3,427 & 22,721 & 0.26 \\
\hline Mean & 8.7 & 412,741 & 11,128 & 96,821 & 0.34 \\
\hline
\end{tabular}

Simulation results (see Table 2) show on average over the 1990-2009 period that a marginal decline in mangrove area leads to a loss of 11.128 tons of shrimp harvest and $€ 96,821$ in revenues from the French Guiana fishery each year and it corresponds to $0.34 \%$ in the annual harvest. We can notice 
two phases of evolution of the mangrove area over the period studied. The first period 1990-1997 shows the mangrove area declining and the losses in terms of harvest varying between 10 and 16 tons on average. A second period 1998-2009 shows mangrove regains area and the losses in terms of harvest varying between 16 and 3 tons. Similarly we can also see that the losses in income are lower in this last period.

\section{Summary and conclusion}

In French Guiana the mangroves colonize almost $75 \%$ of the coastline. We investigate the connection between the mangroves and the shrimp fishery. For this we develop a model that shows how fluctuations in mangrove area can impact the production in the French Guiana shrimp fishery. We first extend an open access bioeconomic model by integrating the mangrove area in the natural growth function. We assume a proportional and positive relationship between mangrove and carrying capacity (Barbier and Starnd, 1998; Barbier, 2000), supported by the positive sign of the coefficient $(\alpha>0)$ associated with. We estimated coefficients of the harvest production function. With the two parameters we derive the level of cost each year that satisfies the open access equilibrium. Finally we evaluate the static effect of mangrove area fluctuations in this fishery.

The mangrove fluctuates naturally and the decline observed over the period 1990-1997 may be caused by to the fluctuations in waves associated with the North Atlantic Oscillation (Walker et al., 2015). Our results show that the financial losses increase when the mangrove decrease in surface and are smaller when the mangroves increase. This suggests that mangrove increase fishery resilience $i$ e face to crisis, and mangrove protection slows the decline of the fishery according to our results. We reccommand therefore to preserve mangrove as possible as the fishery does not totally depend on the mangrove. Nevertheless it remains that the mangroves increase the robustness of the fishery from economic crises or else. Thus a special focus must be carried on the mangrove ecosystems as they are threatened by climate change following Gilman et al. (2007) who consider that the relative sea-level rise may be the greatest threat to mangroves (see also Hoegh-Guldberg and Bruno, 2010; Alongi, 2008).

The extended model, integrating mangrove area, fitted quite well the data. It supports the hypothesis that the mangrove is important in the shrimp production and effort. Integrating mangrove area in the stock dynamic through the environment carrying capacity, can help to understand the mangrove influence in a fishery. The standard bionomic open access 
model (Gordon, 1954), allows for analyze the impacts of mangrove fluctuation on the French Guiana shrimp fishery.

The empirical results show first that the fluctuation in mangrove area leads to same fluctuations in production and revenue as harvest elasticity with respect to the mangrove is positive. Secondly they show that a decrease in effort will lead to a decrease in harvest. Indeed between 1990-2009 the effort level has decreased, like harvest level as the harvest elasticity with respect to the effort is positive. Historitical mangrove area show losses between 1990 and 1997, and gains between 1998 and 2009 period. While the harvest levels decrease between 1998 and 2009, the increase of the mangrove area in the same period did not compensate for the loss of harvest.

The policy implications are not noticeable. If we assume the French Guiana shrimp fishery operating under open access, a mangrove protection or an increase in the mangrove area would not be sufficient to mitigate losses in this fishery. Indeed over the studied period, the losses first was immediately followed by gain in mangrove area, the effort levels continue to decrease and then harvest. The decresase in effort combined with a gain in mangrove would lead to stock recovery. Which was not the case in recent years. Our results imply that mangrove is not the only environmental factor to impact the French Guiana shrimp fishery. The role of mangroves has not been determinant in explaining the collapse of the shrimp stock in French Guiana. This suggests to take into account other factors that play more important role in this fishery (Sanz et al. 2016). 


\section{Appendix}

\section{Appendix A1: The French Guiana shrimp fishery}

Table A1: The French Guiana shrimp fishery

\begin{tabular}{lcccc}
\hline \hline Year & Biomass (tons) & Effort (boat number) & Observed catches (tons) & Mangrove area $\left(\mathrm{km}^{2}\right)$ \\
\hline 1990 & 9831 & 69 & 3926 & 493.41 \\
1991 & 10652 & 54 & 3313 & 483.39 \\
1992 & 11016 & 55 & 3987 & 481.33 \\
1993 & 8929 & 65 & 3275 & 475.91 \\
1994 & 11126 & 58 & 4156 & 467.41 \\
1995 & 10120 & 58 & 4010 & 461.08 \\
1996 & 10304 & 62 & 4323 & 457.07 \\
1997 & 10409 & 59 & 3984 & 451.18 \\
1998 & 9739 & 58 & 3940 & 454.09 \\
1999 & 8765 & 59 & 3495 & 458.22 \\
2000 & 6302 & 52 & 2572 & 459.51 \\
2001 & 6809 & 49 & 2651 & 463.20 \\
2002 & 8120 & 45 & 3043 & 474.75 \\
2003 & 9110 & 46 & 3557 & 482.52 \\
2004 & 8778 & 47 & 3325 & 485.37 \\
2005 & 8026 & 36 & 2943 & 485.51 \\
2006 & 6173 & 24 & 2222 & 490.40 \\
2007 & 6096 & 28 & 2369 & 500.60 \\
2008 & 4000 & 13 & 1496 & 503.82 \\
2009 & 3705 & 12 & 1323 & 498.53 \\
\hline & & & & \\
\hline
\end{tabular}




\section{Appendix A2: Results from open access}

\begin{tabular}{ccc}
\multicolumn{3}{c}{ Table A2 : Results from Open Access } \\
\hline \hline Year & Price $(\mathrm{p}) € / \mathrm{kg}$ & Cost $€ /$ vessel $=\mathrm{c} / \mathrm{pH}$ \\
\hline 1990 & 8.34 & 474,533 \\
1991 & 8.33 & 399,960 \\
1992 & 8.09 & 467,461 \\
1993 & 8.62 & 409,137 \\
1994 & 10.35 & 623,400 \\
1995 & 10.31 & 599,175 \\
1996 & 10.06 & 630,280 \\
1997 & 10.53 & 607,993 \\
1998 & 10.43 & 595,568 \\
1999 & 9.93 & 502,976 \\
2000 & 11.8 & 439,849 \\
2001 & 9.63 & 369,987 \\
2002 & 7.98 & 351,929 \\
2003 & 7.45 & 384,052 \\
2004 & 7.19 & 346,674 \\
2005 & 7.1 & 302,830 \\
2006 & 6.99 & 225,098 \\
2007 & 6.96 & 238,960 \\
2008 & 7.28 & 157,838 \\
2009 & 6.63 & 127,123 \\
& &
\end{tabular}




\section{References}

Alongi, D. M. (2008), "Mangrove forests: resilience, protection from tsunamis, and responses to global climate change" Estuarine, Coastal and Shelf Science, 76(1), 1-13.

Anthony, E. J., Gardel, A., Gratiot, N., Proisy, C., Allison, M. A., Dolique, F., Fromard, F. (2010), "The Amazon-influenced muddy coast of South America: A review of mud-bank-shoreline interactions", Earth-Science Reviews 103(3), 99-121.

Barbier, E. B. (1994), "Valuing environmental function: tropical wetlands", Land Economics 70(2), 155-173.

Barbier, E. B. (2000), "Valuing the environment as input: review of applications to mangrove-fishery linkages", Ecological Economics 35(1), 47-61.

Barbier, E. B., Strand, I. (1998), "Valuing mangrove-fishery linkages: a case stydy of Campeche, Mexico", Environmental Resource Economics 12, 151-166.

Béné, C. (1997), "Dynamique et adaptation d'un système-pêche face aux perturbations de son environnement. Analyses et modélisations dynamiques du couplage écologie- économie; le cas de la pêcherie crevettière guyanaise", Thèse de doctorat.

Bjørndal, T., Conrad, J. M. (1987), "The dynamics of an open access fishery", Canadian Journal of Economics 1, 74-85.

Camacho, A. S., Bagarinao, T. (1987), "The impact of fish pond development on the mangrove ecosystem in the Philippines", In: Mangroves of Asia and the Pacific: Status and Management, pp. 395-405. Technical Report of the UNDP/UNESCO Research and Training Pilot Programme on Mangrove Ecosystems in Asia and the Pacific.

Clark, C. (1976), Mathematical Bioeconomic New York: John Wiley and Sons.

Conrad, J. M. (1995), "Bioeconomic Models of the Fishery", in D. Bromley, ed., Handbook of Environmental Economics, Oxford: Basil Blackwell. 
Day, J.W., Conner, W., Ley-Lou, F., Day, R.H., Navarro, A.M. (1987) "The productivity and composition of mangrove forests, Laguna de Terminos, Mexico", Aquat Bot 27, 267-284.

Faunce, C. H., Serafy1, J. E. (2006), "Mangroves as fish habitat: 50 years of field studies", Marine Ecology Progress Series 318, 1-18.

Gilman, E. L., Ellison, J., Duke, N. C., Field, C. (2008), "Threats to mangroves from climate change and adaptation options: a review", Aquatic botany $89(2), 237-250$.

Gordon, H. (1954), "The conomic theory of a common property", Journal of Political Economy 62(2), 124-142.

Hoegh-Guldberg, O., \& Bruno, J. F. (2010). The impact of climate change on the world's marine ecosystems. Science, 328(5985), 1523-1528.

Homans, F. R., Wilen, J. E. (1997), "A model of regulated open access resource use", Journal of Environmental Economics and Management $32(1), 1-21$.

Mumby, P. J., Edwards, A. J., Arias-González, J. E., Lindeman, K. C., Blackwell, P. G., Gall, A., .Gorczynska, M. I., Harborne, A. R., Pescod, C. L., Renken, H., Wabnitz, C. C., Llewellyn, G. (2004), "Mangroves enhance the biomass of coral reef fish communities in the Caribbean", Nature 427(6974), 533-536.

Nøstbakken, L., Bjørndal, T. (2003), "Supply functions for North Sea herring", Marine Resource Economics 18, 345-361.

Pauly, D., Ingles, J. (1986), "The relationship between shrimp yields and intertidal vegetation (mangrove) areas: a reassessment", In IOC/FAO Workshop on Recruitment in Tropical Coastal Demersal Communities. UNESCO IOC Workshop Report Supplement 44, 277-283.

Rönnbäck, P. (1999), "The ecological basis for economic value of seafood production supported by mangrove ecosystems", Ecological Economics $29(2), 235-252$.

Sanz, N., Diop, B., Blanchard, F., Lampert, L. (2016), "On the influence of environmental factors on harvest : the French Guiana shrimp fishery paradox", Environmental Economics and Policy Studies 18(2), 1-15. 
Serafy, J. E., Shideler, G. S., Araújo, R. J., Nagelkerken, I. (2015), "Mangroves Enhance Reef Fish Abundance at the Caribbean Regional Scale", PLoS ONE 10(11): e0142022. doi:10.1371/journal. pone.0142022

Schaefer, M. (1954), "Some aspects of the dynamics of populations important to the management of commercial marine fisheries", Bulletin of the Inter-American tropical tuna commission 1, 25-26.

Schaefer, M. (1957), "Some Considerations of Population Dynamics and Economics in Relation to the Management of the Commercial Marine Fisheries", Journal of the Fisheries Research Board of Canada 14, 669681.

Smith, V. L. (1969), "On models of commercial fishing", Journal of political Economy 77, 181-198.

Turner, R. E. (1977), "Intertidal vegetation and commercial yields of penaeid shrimp", Transactions of the American Fisheries Society 106(5), 411-416.

Walcker, R., Anthony, E. J., Cassou, C., Aller, R. C., Gardel, A., Proisy, C., Martinez, J. M., Fromard, F. (2015), "Fluctuations in the extent of mangroves driven by multi-decadal changes in North Atlantic waves", Journal of Biogeography 42, 2209-2219. 